\title{
In vitro inhibition of hyaluronidase by sodium copper chlorophyllin complex and chlorophyllin analogs
}

\author{
John P McCook' \\ Peter L Dorogi ${ }^{2}$ \\ David B Vasily \\ Dustin R Cefalo 4 \\ 'Discovery Partners, LLC, Frisco, \\ $\mathrm{TX},{ }^{2} \mathrm{CHL}$ Industries, LLC, Easton, \\ PA, ${ }^{3}$ Aesthetica Cosmetic and Laser \\ Surgery Center, Bethlehem, PA, \\ ${ }^{4}$ Frontier Scientific, Inc., Logan, UT, \\ USA
}

Video abstract

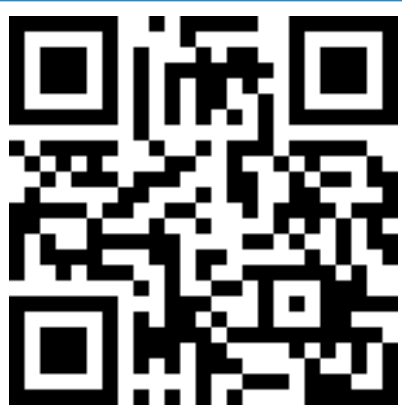

Point your SmartPhone at the code above. If you have a $Q R$ code reader the video abstract will appear. Or use: http://youtu.be/nlsTkR/YGs
Correspondence: John P McCook Discovery Partners, LLC, 4913 Southern Hills Drive, Frisco, TX 75034, USA

$\mathrm{Tel}+\mathrm{I} 2144486513$

Fax +16108618228

Email johnmccook@att.net
This article was published in the following Dove Press journal:

Clinical, Cosmetic and Investigational Dermatology

12 August 2015

Number of times this article has been viewed

Background: Inhibitors of hyaluronidase are potent agents that maintain hyaluronic acid homeostasis and may serve as anti-aging, anti-inflammatory, and anti-microbial agents. Sodium copper chlorophyllin complex is being used therapeutically as a component in anti-aging cosmeceuticals, and has been shown to have anti-hyaluronidase activity. In this study we evaluated various commercial lots of sodium copper chlorophyllin complex to identify the primary small molecule constituents, and to test various sodium copper chlorophyllin complexes and their small molecule analog compounds for hyaluronidase inhibitory activity in vitro. Ascorbate analogs were tested in combination with copper chlorophyllin complexes for potential additive or synergistic activity.

Materials and methods: For hyaluronidase activity assays, dilutions of test materials were evaluated for hydrolytic activity of hyaluronidase by precipitation of non-digested hyaluronate by measuring related turbidity at $595 \mathrm{~nm}$. High-performance liquid chromatography and mass spectroscopy was used to analyze and identify the primary small molecule constituents in various old and new commercial lots of sodium copper chlorophyllin complex.

Results: The most active small molecule component of sodium copper chlorophyllin complex was disodium copper isochlorin e4, followed by oxidized disodium copper isochlorin e4. Sodium copper chlorophyllin complex and copper isochlorin e4 disodium salt had hyaluronidase inhibitory activity down to $10 \mu \mathrm{g} / \mathrm{mL}$. The oxidized form of copper isochlorin e4 disodium salt had substantial hyaluronidase inhibitory activity at $100 \mu \mathrm{g} / \mathrm{mL}$ but not at $10 \mu \mathrm{g} / \mathrm{mL}$. Ascorbate derivatives did not enhance the hyaluronidase inhibitory activity of sodium copper chlorophyllin. Copper isochlorin e4 analogs were always the dominant components of the small molecule content of the commercial lots tested; oxidized copper isochlorin e4 was found in increased concentrations in older compared to newer lots tested.

Conclusion: These results support the concept of using the hyaluronidase inhibitory activity of sodium copper chlorophyllin complex to increase the hyaluronic acid level of the dermal extracellular matrix for the improvement of the appearance of aging facial skin.

Keywords: sodium hyaluronate, extracellular matrix, porphyrin, dermal matrix, glycosaminoglycans, chlorophyll derivative

\section{Introduction}

The extracellular matrix (ECM) present within all tissues and organs provides not only essential physical scaffolding for the cellular constituents but also initiates crucial biochemical and biomechanical signals that are required for tissue morphogenesis, differentiation, and homeostasis. ${ }^{1}$ The ECM is composed of two main classes of macromolecules: proteoglycans, which includes glycosaminoglycan chains, 
primarily hyaluronic acid (HA); and fibrous proteins, which include collagens, elastins, fibronectins, and laminins.

HA is the predominant glycosaminoglycan of human skin, constituting more than $50 \%$ of the total HA in the body. ${ }^{2} \mathrm{HA}$ as an injectable implantable device and dermal filler is approved by the US Food and Drug Administration for correction of facial lines and wrinkles.

Because of its negative charge, HA is highly hydrated and serves as an extracellular reservoir to hold large amounts of cations and water, a mechanism for maintaining normal hydration of the skin. With advancing age, HA polymers become more tissue associated, presumably through HAbinding proteins such as fibrinogen, collagen, CD44, and hyaluronidase, which may underlie some of the changes in human skin that occur with aging. ${ }^{3}$ These changes include loss of moisture in the skin leading to dryness, collagen degradation, loss of elasticity, epidermal atrophy, and wrinkling of the skin. The symptoms of photoaged skin including wrinkling, laxity, and a leather-like appearance are causally connected to histological and ultrastructural changes of the connective tissue of the dermis, including changes in the hyaluronan and proteoglycan matrix leading to reduced water content. ${ }^{4} \mathrm{UVB}$ exposure results in decreased HA in the skin, presumably through down-regulation of HAS2 expression by proteolytic collagen fragments mediated by MMPs in response to UVB. ${ }^{5}$ In mice, subcutaneous estradiol treatment resulted in increased dermal HA, correlated with induction of HAS3, up-regulated by EGF. ${ }^{6}$

HA in tissues is degraded by hyaluronidases, naturally occurring enzymes in the ECM. Degradation of HA in the ECM results in a breakdown of structural integrity and an increase in tissue permeability. ${ }^{7}$ Hyaluronidases in the ECM are present in an inactive or suppressed form, bound to inhibitors. This inhibition of hyaluronidase activity prevents otherwise rapid degradation of HA in the ECM and functions to maintain structural integrity.

Inhibitors of hyaluronidase are also naturally occurring in the ECM and are potent regulating agents involved in maintaining the balance between anabolism and catabolism of HA. The balanced regulation of HA metabolizing enzymes is necessary for normal tissue organization and ECM mediated functions. As agents that maintain HA homeostasis, hyaluronidase inhibitors may serve as antiaging, anti-inflammatory, and anti-microbial agents. ${ }^{8}$ While hyaluronidase inhibitors have not been well characterized, studies suggest that the circulating hyaluronidase inhibitor is a plasma protein with the characteristics of an "I $\alpha \mathrm{I}$ molecule" with a high molecular mass, ranging from 130 to $240 \mathrm{kDa}$ present in the circulation in approximately $0.2-0.7 \mathrm{mg} / \mathrm{mL} .{ }^{4}$ Significant immunohistochemical staining for $I \alpha I$ was observed in the dermis of normal human skin. The authors also describe pericellular (eg, fibroblast) matrix stabilization of hyaluronan with the polypeptide I $\alpha \mathrm{I}$.

Sodium copper chlorophyllin complex is a semi-synthetic mixture of the water-soluble sodium salt of copper chlorophyllin derived from plant chlorophyll that possesses a unique combination of anti-inflammatory, antibacterial, and antioxidant activities. Early research on the pharmacology of chlorophyllins demonstrated the anti-hyaluronidase activity of water-soluble chlorophyllins, suggesting a mechanism for the anti-inflammatory activities observed. ${ }^{9}$

Sodium copper chlorophyllin complex has previously been used topically to aid in wound healing ${ }^{10-13}$ but the ingredient has not been used therapeutically until recently as an anti-aging cosmeceutical in topical cosmetic and personal care products. ${ }^{14}$

Sodium copper chlorophyllin complex is the active component of Phytochromatic MD ${ }^{\mathrm{TM}}$ Complex, which is included in the Rejuvaphyl ${ }^{\mathrm{TM}}$ line of topical products from MDRejuvena, Inc. (San Diego, CA, USA).

The major small molecule analog compounds present in sodium copper chlorophyllin complex have been reported previously ${ }^{15}$ based on high-performance liquid chromatography (HPLC) analysis. In this study, various commercial lots of sodium copper chlorophyllin complex were first analyzed by the method of Mortensen and Geppe ${ }^{15}$ to examine the small molecule constituents in the preparations in advance of screening the lots of sodium copper chlorophyllin complex and their small molecule constituents for hyaluronidase inhibitory activity by an in vitro method. In vitro testing of various known small molecule components of copper chlorophyllin was performed to evaluate their hyaluronidase inhibitory activity. Ascorbic acid and various ascorbate compounds are often included in topical over-the-counter facial skin treatment formulations as antioxidants. Additionally, ascorbate molecules have been cited as inhibitors of hyaluronidase. ${ }^{16}$ Therefore several ascorbate compounds were tested with sodium copper chlorophyllin complex for potential additive or synergistic activity.

\section{Materials and methods Determination of hyaluronidase activity}

Test materials were dissolved in either sterile water or ethanol, as appropriate, immediately before each experiment. 
Test materials were tested at concentrations ranging from $100 \mu \mathrm{g} / \mathrm{mL}$ to $0.4 \mu \mathrm{g} / \mathrm{mL}$. Test material dilutions were made with sterile Type I water. Type I water and ethanol were the negative controls, and the positive control was tannic acid. ${ }^{17}$ (Chemical Abstracts Service number 1401-55-4; SigmaAldrich Co, St Louis, MO, USA), a known strong inhibitor of hyaluronidase activity. ${ }^{18}$ The effect of test materials on the hydrolytic activity of hyaluronidase (IV-S, bovine; SigmaAldrich Co) was assessed by precipitating the non-digested hyaluronate with 10\% cetylpyridinium chloride (Maypro Industries, Purchase, NY, USA) and measuring the related turbidity at $595 \mathrm{~nm}$ with SpectraMax 190 in a manner similar to the method first described in 1948 by Dorfman et al. ${ }^{19}$ Three separate experiments were conducted for each test material. Assays were carried out by Sunny BioDiscovery, Inc., Santa Paula, CA, USA.

All small molecule analog components of sodium copper chlorophyllin complex were supplied by Frontier Scientific, Logan, UT, USA. Sodium copper chlorophyllin (C3999) and ascorbyl palmitate (6-O-palmitoyl-L-ascorbic acid) were supplied by Spectrum Chemical, New Brunswick, NJ, USA. Sodium magnesium chlorophyllin complex (Chlorophyll MM) was supplied by Food Ingredient Solutions, Teterboro, NJ, USA. Sodium ascorbate (Na Asc) and magnesium ascorbyl phosphate (AMP) were supplied by Goodier Cosmetics, Dallas, TX, USA and the dipalmitoyl ascorbate (BV-ADP) was supplied by Barnet Products Corporation, Englewood Cliffs, NJ, USA.

$P$-values representing statistical significance were calculated using paired student's $t$-test, and threshold of statistical significance was fixed at $P=0.05$ and at least $15 \%$ difference as compared to the water control.

\section{Analysis of sodium copper chlorophyllin samples}

Four commercial samples of sodium copper chlorophyllin complex were analyzed by HPLC and mass spectroscopy by Frontier Scientific. The purpose of the analysis was to identify the primary small molecule constituents in each lot using the procedure described by Mortensen and Geppel. ${ }^{15}$ The four samples included both an old and a new lot of sodium copper chlorophyllin complex from two commercial suppliers, Food Ingredient Solutions, LLC and Spectrum Chemical.

Some of the small molecule analog constituents of sodium copper chlorophyllin complex were identified using authentic standards, and others were identified through comparison to the literature.

\section{Results \\ Effect of test materials on hyaluronidase activity in vitro}

Sodium copper chlorophyllin complex, sodium magnesium chlorophyllin complex, and small molecule component compounds of sodium copper chlorophyllin complex were evaluated for hyaluronidase inhibitory activity in vitro, compared to the positive control (tannic acid) and the negative controls (Type I water and ethanol). Three sets of experiments were carried out.

As shown in Table 1 and Figure 1, sodium copper chlorophyllin complex and copper (II) isochlorin e4 disodium salt had hyaluronidase inhibitory activity down to $10 \mu \mathrm{g} / \mathrm{mL}$. The oxidized form of copper (II) isochlorin e4 disodium salt had substantial hyaluronidase inhibitory activity at $100 \mu \mathrm{g} / \mathrm{mL}$ but not at $10 \mu \mathrm{g} / \mathrm{mL}$, and Chlorophyll MM (sodium magnesium chlorophyllin complex) had no activity up to $100 \mu \mathrm{g} / \mathrm{mL}$. The structure of copper isochlorin e4 is shown in Figure 2, and the structure of other copper chlorophyllin analogs are provided in Tumolo and Lanfer-Marquez. ${ }^{20}$

As shown in Table 2, hyaluronidase inhibitory activity of sodium copper chlorophyllin complex was not enhanced by the addition of various ascorbate derivatives, including sodium ascorbate, magnesium ascorbyl phosphate,

Table I Effect of sodium copper chlorophyllin complex, disodium copper isochlorin e4 analogs, and sodium magnesium chlorophyllin complex on hyaluronidase activity in vitro

\begin{tabular}{|c|c|c|c|}
\hline Test material & $\begin{array}{l}\text { Concentration } \\
(\mu \mathrm{g} / \mathrm{mL})\end{array}$ & $\begin{array}{l}\text { Inhibition of } \\
\text { hyaluronidase (\%) }\end{array}$ & $P$-value \\
\hline Water & - & 0 & - \\
\hline Tannic acid & 50 & 100 & 0.000 \\
\hline Sodium copper & 100 & 100 & 0.000 \\
\hline \multirow[t]{3}{*}{ chlorophyllin complex } & 10 & 13 & 0.000 \\
\hline & 2 & 1 & 0.019 \\
\hline & 0.4 & 0 & 0.135 \\
\hline Copper (II) isochlorin & 100 & 100 & 0.000 \\
\hline \multirow[t]{3}{*}{ e4 disodium salt } & 10 & 24 & 0.034 \\
\hline & 2 & 0 & 0.600 \\
\hline & 0.4 & 0 & 0.839 \\
\hline Oxidized form of & 100 & 83 & 0.000 \\
\hline copper (II) isochlorin & 10 & 2 & 0.089 \\
\hline \multirow[t]{2}{*}{ e4 disodium salt } & 2 & 0 & 1.000 \\
\hline & 0.4 & 0 & 1.000 \\
\hline Chlorophyll MM & 100 & II & 0.000 \\
\hline (sodium magnesium & 10 & 1 & 0.839 \\
\hline \multirow[t]{2}{*}{ chlorophyllin complex) } & 2 & 0 & 1.000 \\
\hline & 0.4 & 0 & 1.000 \\
\hline
\end{tabular}




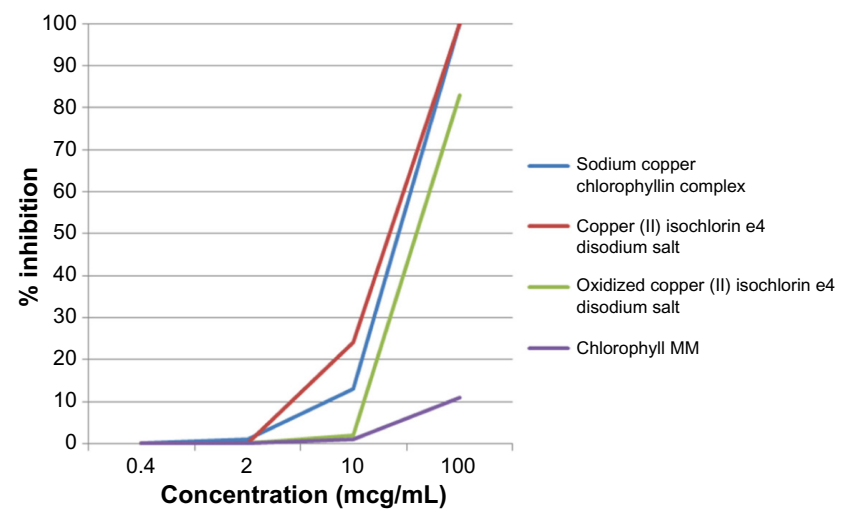

Figure I Inhibition of hyaluronidase as a function of concentration of test materials.

6-O-palmitoyl-1-ascorbic acid, and dipalmitoyl ascorbate. Magnesium ascorbyl phosphate reduced the inhibitory activity of sodium copper chlorophyllin complex.

Various small molecule components of sodium copper chlorophyllin were tested individually for hyaluronidase inhibitory activity. As shown in Table 3, disodium copper isochlorin e4 was the most active material, followed by disodium isochlorin e4. Table 3 does not contain the oxidized forms of the various small molecule components of sodium copper chlorophyllin complex and only the oxidized form

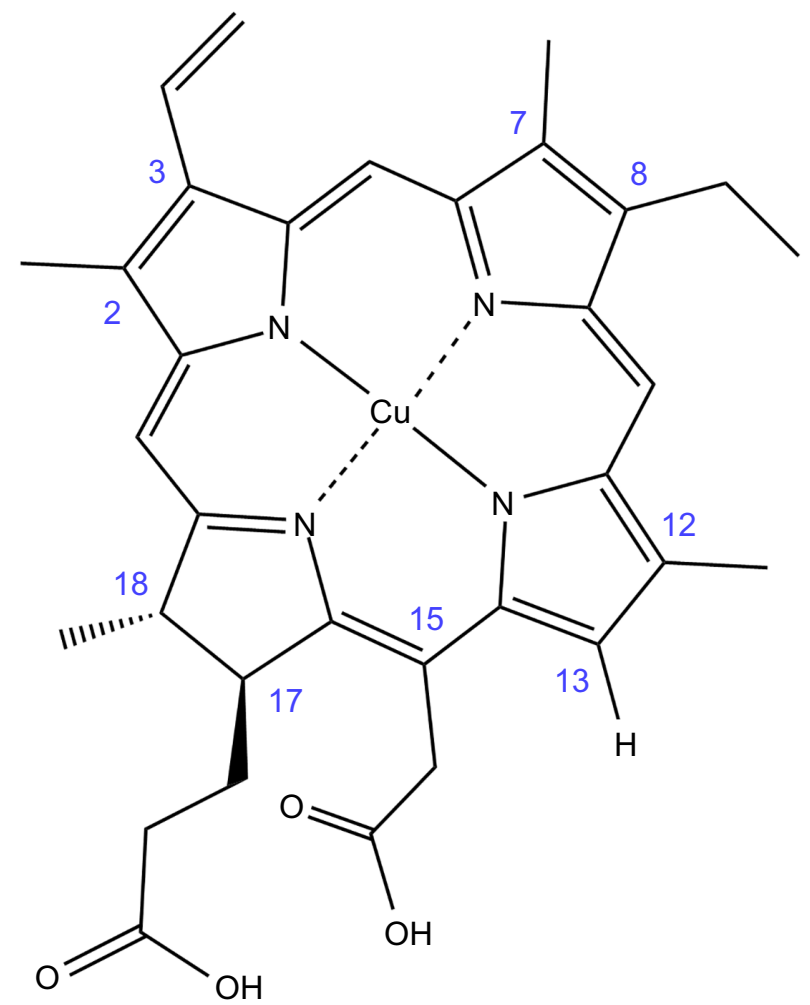

Figure 2 Structure of copper isochlorin e4.

Notes: Structure provided by: Frontier Scientific, Logan, Utah.
Table 2 Effect of sodium copper chlorophyllin complex alone and in combination with ascorbate analogs on hyaluronidase activity in vitro

\begin{tabular}{|c|c|c|c|}
\hline Test material & $\begin{array}{l}\text { Concentration } \\
(\mu \mathrm{g} / \mathrm{mL})\end{array}$ & $\begin{array}{l}\text { Inhibition of } \\
\text { hyaluronidase (\%) }\end{array}$ & $P$-value \\
\hline $\mathrm{H}_{2} \mathrm{O}$ & - & 0 & 1.000 \\
\hline Ethanol, $1 \%$ & - & 0 & 0.650 \\
\hline Tannic acid & 50 & 83 & 0.000 \\
\hline Sodium copper & 100 & 100 & 0.000 \\
\hline \multirow[t]{2}{*}{ chlorophyllin complex } & 20 & 72 & 0.001 \\
\hline & 5 & 5 & 0.072 \\
\hline Sodium copper & 100 & 100 & 0.000 \\
\hline chlorophyllin complex + & 20 & 78 & 0.000 \\
\hline sodium ascorbate & 5 & 4 & 0.033 \\
\hline Sodium copper & 100 & 72 & 0.000 \\
\hline chlorophyllin complex + & 20 & 22 & 0.000 \\
\hline $\begin{array}{l}\text { ascorbyl PM (magnesium } \\
\text { ascorbyl phosphate) }\end{array}$ & 5 & 0 & 0.919 \\
\hline Sodium copper & 100 & 89 & 0.000 \\
\hline chlorophyllin complex + & 20 & 89 & 0.000 \\
\hline $\begin{array}{l}\text { ascorbyl palmitate } \\
\text { (6-O-palmitoyl-L- } \\
\text { ascorbic acid) }\end{array}$ & 5 & 8 & 0.000 \\
\hline Sodium copper & 100 & 100 & 0.000 \\
\hline chlorophyllin complex + & 20 & 83 & 0.003 \\
\hline dipalmitoyl ascorbate & 5 & 4 & 0.035 \\
\hline
\end{tabular}

of copper (II) isochlorin e4, disodium salt was evaluated (Table 1).

\section{Analysis of commercial sodium copper chlorophyllin samples}

Analysis of old and new lots from two commercial suppliers, Food Ingredient Solutions and Spectrum Chemical, showed varying levels of copper isochlorin e4 and oxidized copper isochlorin e4, as shown in Table 4. "New" lots were analyzed within 1 year of production while "old" lots were 4-5 years post-production and had been stored at room temperature $\left(59-86^{\circ} \mathrm{F}\right)$. In addition to the disodium salts of copper isochlorin e4 and oxidized copper isochlorin e4 analogs, smaller percentages of sodium salts of copper chlorin e6, copper chlorin p6, oxidized chlorin p6, oxidized chlorin e6, chlorin e4, and isochlorin e4 were identified in some of the lots. However, the disodium salt of copper isochlorin e4 was always the dominant component of the small molecule content. The disodium salt of oxidized copper isochlorin e4 appears to increase in concentration in the older lots as expected. A representative HPLC chromatogram of an "old" lot from Food Ingredient Solutions is presented in Figure 3. 
Table 3 Effect of sodium copper chlorophyllin small molecule analogs on hyaluronidase activity in vitro

\begin{tabular}{|c|c|c|c|}
\hline Test material & $\begin{array}{l}\text { Concentration } \\
(\mu \mathrm{g} / \mathrm{mL})\end{array}$ & $\begin{array}{l}\text { Inhibition of } \\
\text { hyaluronidase (\%) }\end{array}$ & $P$-value \\
\hline $\mathrm{H}_{2} \mathrm{O}$ & - & 0 & 1 \\
\hline Tannic acid & 50 & 99 & 0.000 \\
\hline Copper (II) isochlorin & 100 & 100 & 0.000 \\
\hline e4 disodium salt & 20 & 60 & 0.000 \\
\hline$(M W=658.16)$ & 5 & 14 & 0.053 \\
\hline Isochlorin e4 & 100 & 55 & 0.000 \\
\hline disodium salt & 20 & 22 & 0.001 \\
\hline$(M W=596.63)$ & 5 & 14 & 0.017 \\
\hline Copper (II) chlorin & 100 & 0 & 0.616 \\
\hline e4 disodium salt & 20 & 12 & 0.079 \\
\hline$(M W=658.16)$ & 5 & 0 & 0.735 \\
\hline Chlorin e4 & 100 & 17 & 0.006 \\
\hline disodiumsalt & 20 & 5 & 0.299 \\
\hline$(M W=596.63)$ & 5 & 9 & 0.115 \\
\hline Copper (II) chlorin & 100 & 24 & 0.006 \\
\hline e6 trisodium salt & 20 & 0 & 0.436 \\
\hline$(M W=724.15)$ & 5 & 5 & 0.382 \\
\hline Chlorin e6 & 100 & 21 & 0.006 \\
\hline trisodium salt & 20 & 20 & 0.002 \\
\hline$(\mathrm{MW}=662.62)$ & 5 & 21 & 0.001 \\
\hline
\end{tabular}

Abbreviation: MW, molecular weight.

\section{Discussion}

HA is a critical component of the ECM necessary for maintaining normal hydration of human skin. The primary mechanism of HA enhancement is through inhibition of hyaluronidase activity by hyaluronidase inhibitors.

Sodium copper chlorophyllin complex, the active component of Phytochromatic MD ${ }^{\mathrm{TM}}$ Complex, demonstrated strong hyaluronidase inhibitory activity in vitro attributable primarily to disodium copper isochlorin e4, a small molecule component of the parent sodium copper chlorophyllin complex. Oxidized isochlorin e4 derivatives demonstrated reduced activity. Hyaluronidase inhibitory activity of sodium copper chlorophyllin was not enhanced by the addition of

Table 4 Analysis of old and new lots of commercial sodium copper chlorophyllin samples for copper isochlorin e4 and oxidized copper isochlorin e4

\begin{tabular}{|c|c|c|c|c|}
\hline \multirow[t]{2}{*}{ Component } & \multicolumn{2}{|c|}{ Food solutions } & \multicolumn{2}{|c|}{ Spectrum } \\
\hline & Old lot & New lot & Old lot & New lot \\
\hline $\begin{array}{l}\text { Copper isochlorin e4, } \\
\text { disodium salt }\end{array}$ & $41 \%$ & $24 \%$ & $\begin{array}{l}\text { None } \\
\text { detected }\end{array}$ & $50 \%$ \\
\hline $\begin{array}{l}\text { Oxidized copper isochlorin } \\
\text { e4, disodium salt }\end{array}$ & $26 \%$ & $18.7 \%$ & $21 \%$ & $12 \%$ \\
\hline
\end{tabular}

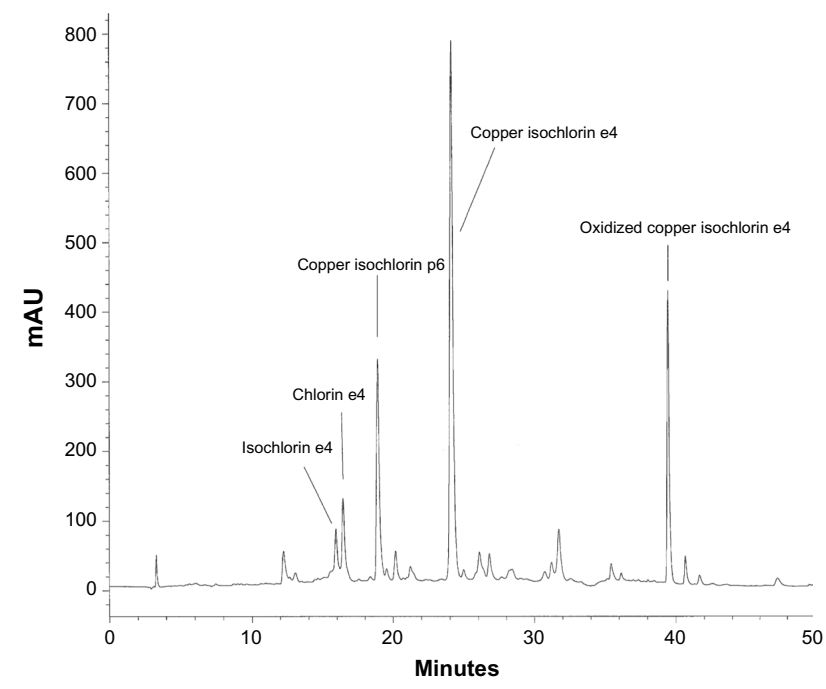

Figure 3 HPLC chromatogram of sodium copper chlorophyllin, item number P552 I from Food Ingredient Solutions, lot number 200/98 ("old lot").

Notes: HPLC analysis was performed using YMC C30 column, $(250 \times 4.6 \mathrm{~mm})$, $405 \mathrm{~nm}$. The gradient program used was: $0-50 \%$ B over 30 minutes, $50-100 \%$ B over 10 minutes, $100 \%$ B for 5 minutes and $100-0 \%$ B over 5 minutes. Solvent A: methanol:water: acetic acid (90:10:0.5) and Solvent B: tert-butyl methyl ether:methanol:acetic acid (100:10:0.5) at a flow rate of $1.1 \mathrm{~mL} / \mathrm{min}$.

Abbreviation: HPLC, high-performance liquid chromatography.

various ascorbate derivatives. The results indicate that copper is an important component of the inhibitory activity, given the lack of inhibitory activity seen with sodium magnesium chlorophyllin complex. Although not tested, natural chlorophyll extracts from plant sources are magnesium chelates of chlorophyll and would therefore not be expected to show hyaluronidase inhibitory activity.

Analysis of various commercial lots of sodium copper chlorophyllin complex showed that the primary small molecule component, as found in newer lots, was disodium copper isochlorin e4. Older lots had proportionally higher amounts of disodium oxidized copper isochlorin e4, which demonstrated lower hyaluronidase inhibitory activity in vitro.

Topical application of sodium copper chlorophyllin complex may be useful in the regulation of HA by inhibition of hyaluronidase activity in the skin, thereby acting to enhance the improvement in the appearance of facial skin.

Complete inhibition of hyaluronidase activity in vitro was demonstrated at sodium copper chlorophyllin complex concentrations substantially lower than those found in Phytochromatic MD ${ }^{\mathrm{TM}}$ complex. Sodium copper chlorophyllin complex is present at concentrations of $250-1,000 \mu \mathrm{g} / \mathrm{mL}$ in Phytochromatic MD ${ }^{\text {TM }}$ complex, an enhanced penetrating liposomal concentrate of sodium copper chlorophyllin complex, as utilized in various topical anti-aging treatment products developed by MDRejuvena, Inc. 


\section{Conclusion}

These results support the concept of using the hyaluronidase inhibitory activity of sodium copper chlorophyllin complex, alone or together with other topical cosmeceuticals, for example, retinoids, alpha-hydroxy acids, and anti-aging peptides, in order to improve the appearance of aged or photoaged skin; particularly improvements related to the integrity of the dermal matrix.

\section{Acknowledgment}

Medical writing assistance was provided by Georgia Theofan, PhD of ProPharmaCon LLC of San Diego, CA, USA.

\section{Disclosure}

Authors McCook, Dorogi, and Vasily are partners in CHL Industries, LLC, Licensor of the Phytochromatic MD ${ }^{\mathrm{TM}}$ technology described in this article. The authors report no other conflicts of interest in this work.

\section{References}

1. Frantz C, Stewart KM, Weaver VM. The extracellular matrix at a glance. J Cell Sci. 2010;123(Pt 24):4195-4200.

2. Manuskiatti W, Maibach HI. Hyaluronic acid and skin: wound healing and aging. Int J Dermatol. 1996;35(8):539-544.

3. Meyer LJ, Stern R. Age-dependent changes of hyaluronan in human skin. J Invest Dermatol. 1994;102(3):385-389.

4. Röck K, Fischer JW. Rolle der extrazellulären Matrix bei der extrinsischen Hautalterung [Role of the extracellular matrix in extrinsic skin aging]. Hautarzt. 2011;62(8):591-597. German.

5. Röck K, Grandoch M, Majora M, Krutmann J, Fischer JW. Collagen fragments inhibit hyaluronan syntheses in skin fibroblasts in response to ultraviolet B (UVB): new insights into mechanisms of matrix remodeling. J Biol Chem. 2011;286(20):18268-18276.
6. Röck K, Meusch M, Fuchs N, et al. Estradiol protects dermal hyaluronan/versican matrix during photoaging by release of epidermal growth factor from keratinocytes. J Biol Chem. 2012;287(24):20056-20069.

7. Mio K, Stern R. Inhibitors of the hyaluronidases. Matrix Biol. 2002; 21(1):31-37.

8. Girish KS, Kemparaju K, Nagaraju S, Vishwanath BS. Hyaluronidase inhibitors: A biological and therapeutic perspective. Curr Med Chem. 2009; 16(18):2261-2288.

9. Barnard RD, Goldman B, Kessler LN, Stanton HT Jr. Heparinic effects of cupridihydroporphyrins (eater-soluble chlorophyllins). J Am Pharm Assoc Am Pharm Assoc (Baltim). 1954;43(2):110-113.

10. Bowers WF. Chlorophyll in wound healing and suppurative disease. Am J Surg. 1947;73(1):37-50.

11. Carpenter EB. Clinical experience with chlorophyll preparations. Am J Surg. 1949;77(2):167-171.

12. 2004 Physicians' Desk Reference. 58th ed. Stamford: Thomson Health Care, Inc.; 2003.

13. Smith RG. Enzymatic debriding agents: an evaluation of the medical literature. Ostomy Wound Manage. 2008;54(8):16-34.

14. Sigler ML, Stephens TJ. Assessment of the safety and efficacy of topical copper chlorophyllin in women with photodamaged skin. $J$ Drugs Dermatol. 2015;14(4):401-404

15. Mortensen A, Geppel A. HPLC-MS analysis of the green food colorant sodium copper chlorophyllin. Innovative Food Science and Emerging Technologies. 2007;8:419-425.

16. Botzki A, Rigden DJ, Braun S, et al. L-ascorbic acid 6-hexadecanoate, a potent hyaluronidase inhibitor. J Biol Chem. 2004;279(44): 45990-45997.

17. Sumantran VN, Kulkarni AA, Harsulkar A, et al. Hyaluronidase and collagenase inhibitory activities of the herbal formulation Triphala guggulu. J Biosci. 2007;32(4):755-761.

18. Satardekar KV, Deodhar MA. Anti-ageing ability of Terminalia species with special reference to hyaluronidase, elastase inhibition and collagen synthesis in vitro. International Journal of Pharmacognosy and Phytochemical Research. 2010;2(3):30-34.

19. Dorfman A, Ott ML, Whitney R. The hyaluronidase inhibitor of human blood. J Biol Chem. 1948;174(2):621-629.

20. Tumolo T, Lanfer-Marquez UM. Copper chlorophyllin: a food colorant with bioactive properties? Food Research International. 2012; $46(2): 451-459$.
Clinical, Cosmetic and Investigational Dermatology

\section{Publish your work in this journal}

Clinical, Cosmetic and Investigational Dermatology is an international, peer-reviewed, open access, online journal that focuses on the latest clinical and experimental research in all aspects of skin disease and cosmetic interventions. All areas of dermatology will be covered; contributions will be welcomed from all clinicians and

\section{Dovepress}

basic science researchers globally. This journal is indexed on CAS The manuscript management system is completely online and includes a very quick and fair peer-review system, which is all easy to use. Visit http://www.dovepress.com/testimonials.php to read real quotes from published authors. 